\title{
Kidney disease and the cumulative burden of life course socioeconomic conditions: The Atherosclerosis Risk in Communities (ARIC) Study ${ }^{\text {is }}$
}

\author{
David A. Shoham ${ }^{\text {a,b,c, } * \text {, Suma Vupputuri }}{ }^{\mathrm{b}}$, Jay S. Kaufman ${ }^{\mathrm{b}}$, Abhijit V. Kshirsagar ${ }^{\mathrm{c}}$, \\ Ana V. Diez Roux ${ }^{\mathrm{d}}$, Josef Coresh ${ }^{\mathrm{e}}$, Gerardo Heiss ${ }^{\mathrm{b}}$ \\ a Department of Preventive Medicine and Epidemiology, Loyola University Chicago, Maywood, IL 60153, United States \\ ${ }^{\mathrm{b}}$ Department of Epidemiology, UNC, Chapel Hill, NC, United States \\ ${ }^{\mathrm{c}}$ UNC Kidney Center, UNC, Chapel Hill, NC, United States \\ ${ }^{\mathrm{d}}$ Department of Epidemiology, University of Michigan, Ann Arbor, MI, United States \\ e Department of Epidemiology, Johns Hopkins University, Baltimore, MD, United States
}

\section{A R T I C L E I N F O}

\section{Article history:}

Available online 28 July 2008

\section{Keywords:}

Kidney diseases

Residence characteristics

Social class

Race disparities

Life course

USA

Cohort study

\begin{abstract}
A B S T R A C T
The authors investigated the cumulative effects of life course social class and neighborhood socioeconomic conditions on the prevalence of chronic kidney disease (CKD) in adulthood. Subjects were members of the Atherosclerosis Risk in Communities (ARIC) Study, a longitudinal cohort study of four US communities. CKD was defined by glomerular filtration rate $<45 \mathrm{ml} / \mathrm{min} / 1.73 \mathrm{~m}^{2}$ or hospital discharge diagnosis. Working class was defined by workplace roles for subjects and their fathers; area socioeconomic status (SES) was based on census information. Being working class for all life course periods or for some life course periods was associated with increased odds of CKD, compared to being non-working class for all periods (adjusted odds ratio, OR, for all periods (95\% confidence interval) $1.4(0.9,2.0)$ in Whites and $1.9(1.3,2.9)$ in African-Americans; OR for some periods $1.3(1.0,1.9)$ in Whites and $1.4(0.9,2.2)$ in African-Americans). Low area SES over the life course was not significantly related to CKD compared to living in a higher SES areas at all life course periods. Adjustment for age, gender, community of residence, cumulative social class (for neighborhood measures), cumulative low-neighborhood SES (for cumulative individual social class), hypertension and diabetes does not account for these associations.

Our conclusion is that chronic kidney disease is associated with life course socioeconomic conditions. As such, life course social class and neighborhood conditions deserve further attention in accounting for socioeconomic disparities in kidney disease.
\end{abstract}

(c) 2008 Elsevier Ltd. All rights reserved.

\footnotetext{
is The Atherosclerosis Risk in Communities Study is carried out as a collaborative study supported by National Heart, Lung, and Blood Institute contracts N01-HC-55015, N01-HC-55016, N01-HC-55018, N01-HC-55019, N01-HC-55020, N01-HC-55021, and N01-HC-55022. The authors thank the staff and participants of the ARIC Study for their important contributions. DAS and SV were supported by National Institutes of Health-National Institute of Diabetes Digestive and Kidney Diseases, \#R21DK68354-01A1; DAS was also supported by an institutional training grant in renal epidemiology, \#5T32DK007750-07. ADR was supported in part by R24 HD047861 (CHUMS). This work was completed while DAS was a post-doctoral trainee at UNC, Chapel Hill; he is now affiliated with the Department of Preventive Medicine, Stritch School of Medicine, Loyola University Chicago.

* Corresponding author. Department of Preventive Medicine and Epidemiology, Loyola University Medical Center, 2160 S. First Ave., Maywood, IL 60153, USA. Tel.: +1 7083279006 .

E-mail addresses: dshoham@lumc.edu (D.A. Shoham), suma_vupputuri@kp.org (S. Vupputuri), jay_kaufman@unc.edu (J.S. Kaufman), abhijit_kshirsagar@med.unc.edu (A.V. Kshirsagar), adiezrou@umich.edu (A.V. Diez Roux), coresh@jhu.edu (J. Coresh), gerardo_heiss@unc.edu (G. Heiss).
} 


\section{Main text}

Social conditions, including social class, race, income, and education level, have been called "fundamental causes of disease" because they entail unequal access to healthpromoting and disease-avoiding resources, thereby structuring disease risk in manifold ways (Link \& Phelan, 1995). According to Link and Phelan, such resources include "money, knowledge, power, prestige, and ... interpersonal resources" (p. 87). Social conditions have received a great deal of attention in cardiovascular, cancer, and infectious disease epidemiology.

Relatively few studies have investigated the association between social conditions and kidney disease, apart from research on racial differences (Shoham, Vupputuri, \& Kshirsagar, 2005). African-Americans have 3.8-fold the endstage renal disease (ESRD) incidence of Whites (USRDS, 2004), and studies have documented racial disparities in kidney disease (Byrne, Nedelman, \& Luke, 1994; Fored et al., 2003; Krop et al., 1999; Perneger, Whelton, \& Klag, $1995 b)$. Race is a social construct, not an essential biological category (AAA, 1998; AAPA, 1996). In the United States, race is highly correlated with socioeconomic conditions. African-Americans are much more likely than Whites to be members of the urban 'underclass' and reside in areas of intensely concentrated poverty (Wilson, 1990), and they are less likely than Whites to accumulate wealth (Conley, 1999; Oliver \& Shapiro, 1995). Link and Phelan (1995) emphasize that race is itself so closely tied to resources that it should also be considered a fundamental cause of health inequality. These findings suggest an etiologic role for social conditions in kidney disease.

The social distribution of biological risk factors provides further evidence in favor of a social causation hypothesis for kidney disease. Hypertension and diabetes mellitus are strongly associated with disadvantaged socioeconomic position (Brancati, Whelton, Kuller, \& Klag, 1996; Connolly \& Kesson, 1996; Frank, Cohen, Yen, Balfour, \& Smith, 2003; James, Keenan, Strogatz, Browning, \& Garrett, 1992; Perneger, Klag, \& Whelton, 1995a; Pickering, 1999; Robbins, Vaccarino, Zhang, \& Kasl, 2001). Hypertension and diabetes underlie over $70 \%$ of all prevalent cases of ESRD (USRDS, 2003), and these two conditions have been the focus of most etiologic research; they are also strongly associated with earlier stages of chronic kidney disease (CKD) (Coresh, Longenecker, Miller, Young, \& Klag, 1998; Jones et al., 2002; Vupputuri et al., 2003). Potential mechanisms translating social disadvantage into kidney disease may also include isolation, infectious agents, and access to care (Cass, Cunningham, Snelling, Wang, \& Hoy, 2004; Shoham et al., 2005).

Three models have been proposed to explain how socioeconomic position over the life course may influence adult health: critical periods, cumulative exposures, and trajectory effects (Blane, 1999). We investigated the critical periods model in a previous paper (Shoham et al., 2007). This model posits that exposures occurring at critical periods in the life course (particularly gestation and infancy) have long-lasting effects on health later in life. Barker has used this model to show that adult hypertension is the consequence of prenatal conditioning (Barker, Osmond, \& Law,
1989), while Brenner established a link between birthweight, number of glomeruli, and adult hypertension and kidney disease (Brenner, Garcia, \& Anderson, 1988; Brenner \& Gertow, 1994). In our previous analysis, we asked whether childhood or adulthood social class is more important for determining later-adult kidney disease risk, and within adulthood, if there are particular ages at which being working class increases the risk of later disease. Distinct models were used for each time period, comparing odds of CKD in middle age among working vs. non-working class subjects. Because neighborhoods may also exert effects on disease, we calculated composite scores of area disadvantage at the census tract level (lowest tertile of $z$-scores), using the same four time periods. The definitions of social class, $z$-score tertiles, and the outcome measures of CKD that were used in the previous analysis are described in further detail in the Materials and Methods section below. The previous study found that being working class at age 30 increased the odds of CKD by approximately $40 \%$ among Whites and 90\% among African-Americans, when compared to non-working class members within the same race group. On the other hand, in the previous study, low area SES was most strongly associated with CKD at age 50 , with approximately $60 \%$ increased odds among Whites and 50\% increased odds among African-Americans. In contrast to prior theory, our previous study did not find evidence of independent effects of father's social class or of living in a low SES area during childhood on subject's odds of CKD later in life.

Our previous analysis, however, did not take account of the sum total of socioeconomic influences acting across the life course, but rather focused on particular periods. Although the effects of childhood living conditions may not exert an independent effect on adult disease risk, they may nevertheless increase the likelihood of disease when combined with socioeconomic position later in life. This second life course model considers cumulative exposures to adverse social circumstances over sustained periods such as poverty, jobs with little autonomy, and living in a poor neighborhood - the salient determinants of chronic disease. We plan to address the third model, of life course trajectories, in a future report.

In this paper, we investigate whether being of low social class and living in a disadvantaged neighborhood across the life course are associated with increased odds of having CKD in adulthood (i.e., cumulative effects of social class and neighborhood conditions). Specifically, we hypothesize that persons with greater cumulative life course exposure to being low social class and living in a low SES neighborhood will have greater odds of CKD than those with less life course exposure to socioeconomic disadvantage.

\section{Materials and methods}

Subjects were members of the Life Course Socioeconomic Status (LCSES) ancillary study of the Atherosclerosis Risk in Communities (ARIC) Study, a longitudinal cohort study of 15,792 White and African-American men and women residing in four U.S. communities: Jackson, Mississippi; Forsyth County, North Carolina; the suburbs of Minneapolis, Minnesota; and Washington County, Maryland 
(The ARIC Investigators, 1989). At the time of recruitment (1987-1989), subjects ranged in age from 45 to 64 years old. Serum creatinine measures were obtained from subjects during at least one of three follow-up visits; measures were calibrated to the Cleveland Clinic Laboratory, allowing comparison with the Third National Health and Nutrition Examination Survey. Follow-up information on hospital discharge diagnoses was obtained and confirmed through 2002.

The LCSES is an ancillary study to the primary ARIC Study, designed as a retrospective cohort. During the 2001 annual follow-up interview, subjects were asked questions about their own socioeconomic circumstances and historical addresses at ages 30,40, and 50 and parental and childhood social circumstances and place of residence at age 10 . There were 12,681 questionnaires returned by subjects (80.5\% of original cohort), of whom 12,670 had at least one serum creatinine measure and were either of African-American or White race. Exclusions were made for African-Americans living in Minneapolis and Maryland $(n=39)$. Mean age at the time of questionnaire completion was 67.4 years (range: $56-80$ ), an average of 13.8 years after the initial ARIC visit. Historical addresses were geocoded and placed in the appropriate census tract for ages 3050 ; for age 10 , tracts were not available and county data were used. The accuracy and repeatability of the geocoding process for this study have been reported elsewhere (Whitsel et al., 2004).

\section{Individual socioeconomic position}

We chose social class as the individual-level measure for several reasons. First, social class is a determinant of income level, education, psychosocial stress (Oakes \& Rossi, 2003; Wohlfarth, 1997), and health behaviors, habits, and lifestyle (Bourdieu, 1984; Lynch, Kaplan, \& Salonen, 1997). Class analysis is based on the theory that classes represent antagonistic and interacting material interests, rather than merely a "set of statuses" (p. 12) (Wright, 1996). Class theorists argue that inequalities captured by continuous SES measures (such as income level and wealth) are merely the consequences of power relationships, rather than the salient characteristics of social structure (Horan, 1978; Oakes \& Rossi, 2003; Wright, 1996). Power is thus the salient characteristic we capture by using social class. Practically, social class may be measured retrospectively, whereas income level is difficult to recall and is rarely (if ever) used in retrospective studies.

Individual socioeconomic positions for subjects at ages 30,40 , and 50 were obtained using five questionnaire items: (1) "did you complete college or more education?"; (2) "were you self-employed?"; (3) "did you hold a managerial position?"; (4) "did you supervise the work of other employees, have responsibility for or tell other employees what to do?"; and (5) "did you participate in making decisions about such things as the products and services offered, the total number of people employed, budgets and so forth?". Following Wright's work on operationalizing social class (Wright, 1989, 1996), we employed a reduced classification scheme for social class. Subjects who answered "no" to every one of these five questions were classified as "working class"; subjects who answered "yes" to at least one of these questions were classified as "non-working class," the reference category. We choose this dichotomization as the definition of "working class" for two reasons. Theoretically, "working class" corresponds to the least powerful class category in Wright's work. Those who are "non-working class" thus have a degree of power in at least one of three dimensions: skills, ownership, or authority. The second reason for this choice was statistical power; we lacked sufficient number of cases needed to explore more fine-grained class schemas, such as the seven aggregated classes analyzed in Class Counts (Wright, 1996). Similar questions were asked of subjects regarding the class of his or her father or important male caretaker (hereafter referred to as "father"). Fathers were also categorized as farmers or non-farmers.

\section{Area-level socioeconomic status}

Area-level socioeconomic status (area SES) was assessed by linking the geocoded historical addresses of respondents with decennial census data. SES for area of residence was measured at the county level for childhood (census years 1930-1950), and at the census tract level for ages 30, 40, and 50 (census years: 1960-2000). Principle components' analyses (PCA) of area-level SES attributes were conducted for each decennial census. Up to 15 variables were used for age 10 county measures; 12 used for age 30,11 for age 40 , and 13 used at age 50; not all variables were available across all years. Area SES variables incorporated into the final area score included log median housing unit value, log mean income level, unemployment, number of people per room, percent high school and college educated, percent professional, and percent home ownership. These were converted to $z$-scores, created by subtracting the mean value for a particular census variable on a given census year from the value for a particular subject's county or census tract, then dividing by the standard deviation; the $z$ scores are census-specific. First component loadings from the PCA were used to generate a weighted sum of $z$-scores for each tract or county, and loaded most heavily on four characteristics: log household income, percent professional or managerial occupations, percent with at least a high school education, and log of mean home value. Table 1 shows the first and second component loadings. This first component captured from $40 \%$ to $50 \%$ of the variance in area SES. The second component, which weighted on household characteristics (percent living alone, percent of units occupied), captured less than $20 \%$ of variance. Household characteristics were disregarded because they explained less between-neighborhood variance than socioeconomic characteristics; furthermore, household characteristics had not been hypothesized to increase risk of CKD. The area-level scores are therefore interpreted as a summary measure of area-level resources, as opposed to family structure or housing characteristics.

\section{Life course scores}

A cumulative measure was created based on subject's father's social class (a proxy for childhood socioeconomic 
Table 1

Principle components loadings on first and second components, by decennial census

\begin{tabular}{|c|c|c|c|c|c|c|}
\hline \multirow[t]{2}{*}{ Principle component } & \multicolumn{2}{|l|}{ Age 30} & \multicolumn{2}{|l|}{ Age 40} & \multicolumn{2}{|l|}{ Age 50} \\
\hline & $\begin{array}{l}\text { First: } \\
\text { socioeconomic }\end{array}$ & $\begin{array}{l}\text { Second: household } \\
\text { characteristics }\end{array}$ & $\begin{array}{l}\text { First: } \\
\text { socioeconomic }\end{array}$ & $\begin{array}{l}\text { Second: household } \\
\text { characteristics }\end{array}$ & $\begin{array}{l}\text { First: } \\
\text { socioeconomic }\end{array}$ & $\begin{array}{l}\text { Second: household } \\
\text { characteristics }\end{array}$ \\
\hline Variance explained by component & $41 \%$ & $18 \%$ & $42 \%$ & $16 \%$ & $50 \%$ & $17 \%$ \\
\hline \multicolumn{7}{|l|}{ Variable } \\
\hline Average number of people per household & 0.04 & 0.55 & & & & \\
\hline Average number of people per room & -0.27 & 0.25 & -0.30 & -0.09 & -0.31 & -0.07 \\
\hline Housing stability & 0.11 & -0.18 & 0.11 & 0.15 & 0.01 & -0.24 \\
\hline Log of average or median income & 0.39 & -0.09 & 0.38 & 0.19 & 0.32 & 0.24 \\
\hline Log of home value & 0.38 & -0.08 & 0.36 & 0.24 & 0.31 & 0.26 \\
\hline Percent households in poverty & & & & & -0.35 & 0.13 \\
\hline Percent living alone & -0.18 & -0.54 & -0.14 & 0.58 & -0.12 & 0.49 \\
\hline Percent of dwelling units occupied & 0.12 & 0.26 & 0.15 & -0.40 & 0.22 & -0.35 \\
\hline Percent of owner occupied housing units & 0.26 & 0.39 & 0.26 & -0.48 & 0.26 & -0.37 \\
\hline Percent professional occupations & 0.38 & -0.15 & 0.37 & 0.07 & 0.29 & 0.24 \\
\hline Percent single family households & & & & & -0.32 & 0.24 \\
\hline Percent unemployed & -0.27 & -0.10 & -0.24 & 0.32 & -0.30 & 0.17 \\
\hline Percent with college education & 0.35 & -0.13 & 0.36 & 0.20 & 0.26 & 0.32 \\
\hline Percent with high school education & 0.40 & -0.09 & 0.41 & 0.09 & 0.34 & 0.22 \\
\hline Total population & 0.09 & 0.13 & 0.10 & 0.01 & & \\
\hline
\end{tabular}

position) and subjects' own social class at age 30,40 , and 50 . Subjects were placed into one of three categories based on the cumulative measure: working class across the life course; working class during at least one period (but not all four periods); and non-working class across the life course. Subjects who were homemakers at any point up to age 50 were classified as "some periods working class" if they were working class at any period, and "non-working class" if they were never working class. Life course area SES was defined as follows: first, areas were divided into racespecific tertiles based on area SES scores from the PCA, with the lowest tertile representing "low area SES" for each period. Next, the number of life course periods spent living in a low SES area was summed. Living in a low SES area for all periods thus yielded a score of 4 , while 0 was the score for those never having lived in a low SES area; those who lived in a low SES area for some but not all periods of the life course had a score of 1,2 , or 3 . Tests of trend were conducted for both social class and area SES in the following manner: being working class (or living in a low SES area) at all four periods was coded as a score of 1 ; at some but not all (1-3 out of 4 ) periods was scored 0.5 ; and no periods working class (or living in a low SES area) was scored 0 . The trend variable was then introduced into the logistic model in place of social class (or area SES), and a Wald test $p$-value for the variable was estimated.

\section{Outcome measures}

The outcome of these analyses was chronic kidney disease. CKD was defined as having either a glomerular filtration rate (GFR) below $45 \mathrm{ml} / \mathrm{min} / 1.73 \mathrm{~m}^{2}$ or having ICD-9 annual follow-up hospital discharge diagnosis of CKD (250.4x, 403.x, 581.x, 582.x, 583.x, 585.x, 586.x, 587.x, $588 . x, v 42.0, v 45.1,39.95$, or 54.98 ) at any time through the end of 2002. GFR was estimated from serum creatinine, age, gender, and race using the Modification of Diet in Renal Disease (MDRD) abbreviated study equation, and are reported in units of $\mathrm{ml} / \mathrm{min} / 1.73 \mathrm{~m}^{2}$ (NKF, 2002). The last available serum creatinine was used; for 10,701 subjects (84.5\%), this was the fourth visit (1996-1998), while for others, the values at first (1987-1989; $n=1497)$ or second visit (1990-1992; $n=472)$ were used.

We chose a GFR cutpoint of $45 \mathrm{ml} / \mathrm{min} / 1.73 \mathrm{~m}^{2}$, since this cutpoint shows a dramatically higher risk of complications than the traditional cutpoint of $60 \mathrm{ml} / \mathrm{min} / 1.73 \mathrm{~m}^{2}$ (Go, Chertow, Fan, McCulloch, \& Hsu, 2004) and conservatively accounts for ARIC being a healthy general population sample. Furthermore, the MDRD estimation equation is more accurate at lower GFR (Levey et al., 2006; Stevens, Coresh, Greene, \& Levey, 2006). These definitions were combined to yield a summary outcome measure of prevalent chronic kidney disease. In order to assess sensitivity of our results to the outcome definition, age-adjusted tests of trend for increasing periods spent as members of the working class and living in low SES areas were conducted using outcome definitions based only on ICD-9 diagnosis and only on GFR below $45 \mathrm{ml} / \mathrm{min} / 1.73 \mathrm{~m}^{2}$.

\section{Imputation}

Many subjects were missing area-level information (the primary reason for missing data): at age 50, 802 (6.4\%); at age 40, 2533 (20.1\%); at age 30, 6726 (53.2\%); and at age 10, 2527 (20.0\%). Much of the country was not tracted in 1960 and 1970 (Anderson, 2000), the census years when most subjects were 30 years old. For each $\$ 25,000$ greater difference in household income, Whites had 0.8 times the odds of missing data (95\% confidence interval, CI: 0.6, 1.0), while there was no association between income and missing data among African-Americans (95\% CI: 0.5, 2.3). In order to avoid biased results, Bayesian multiple imputation was conducted using the STATA (StataCorp: College Station, TX) user-written program MVIS (Royston, 2004), as described elsewhere (Shoham et al., 2007). The resulting scores were categorized into race-specific tertiles, which were used in the final analysis. In order to gauge the degree to which imputation affected parameter estimation, all 
analyses were repeated using the complete-case (non-imputed) data set.

\section{Race stratification}

All analyses were conducted in race-specific strata. The rationale for doing so is threefold. First, given the correlation between race and socioeconomic conditions at the individual (social class) and neighborhood levels, we sought to characterize the effect of social class within race groups. Nevertheless, readers may be interested in whether there was heterogeneity of class associations by race, so we formally assessed heterogeneity by including interaction terms of race by cumulative social class (being working class in any vs. no periods) using the Walk chisquare test. Second, models where the exposure of interest is a social variable may give misleading results when adjusted for race due to residual confounding (Kaufman \& Cooper, 1999; Kaufman, Cooper, \& McGee, 1997). The preferred approach in such situations is to stratify by race. Third, the socioeconomic characteristics of neighborhoods differ widely by race in the United States, as already noted in describing the construction of race-specific tertiles. This phenomenon has been deemed "structural confounding" by Oakes (2006), and it precludes direct comparison of neighborhood characteristics across race groups.

\section{Statistical analysis}

We initially compared means and proportions of participants' clinical and demographic characteristics by race and disease status within race using $t$-tests (for means) and Wald chi-square tests (for proportions).

A logistic regression model was used to assess the odds of CKD associated with being working class across the life course and being working class at just some periods, compared to those who were non-working class at every period. Using the same model, the odds of CKD among those living in the lowest tertile of area-level SES across all periods or at just some periods were compared to odds of CKD in those living in a middle or high tertile area at all periods.

Measures of association were adjusted for age at the first ARIC examination (Model 1) or age in combination with gender, father having been a farmer, and study center (Model 2). In Model 2, individual class measures were included in the same model as area-level measures, since class may be a confounder of area-level measures. By "potential confounder", we here mean a characteristic meeting three criteria: (1) the characteristic is associated with kidney disease; (2) the characteristic is associated with individual social class (or area SES); and (3) the characteristic must temporally precede social class (or area SES) and kidney disease, that is, it cannot be a causal intermediate linking social class and kidney disease (Rothman \& Greenland, 1998). Our choice of confounders is further consistent with graphical and counterfactual criteria for model specification in estimating causal effects (Pearl, 2000). In order to avoid biased results, Bayesian multiple imputation was conducted using the STATA (StataCorp: College Station,
TX) user-written program MVIS (Royston, 2004); details of the approach used are described elsewhere (Shoham et al., 2007). Models were run for each imputation and were combined using SAS PROC MIANALYZE (SAS Institute: Cary, NC).

Subsequent models were similar to Model 2, but further adjusted for hypertension or diabetes mellitus (labeled "Model 3" in the results section and tables). Adjustment was made for these potential causal intermediates in order to estimate the direct effect of social factors on kidney disease. By the direct effect, we mean the effect that is not transmitted through the effect of social factors on these other chronic conditions (Robins \& Greenland, 1992). We emphasize that this estimated "direct effect" does not estimate the total causal association between social class and CKD, only that part of the association not mediated by diabetes and hypertension. The unbiased estimation of the direct effect depends on additional no-confounding assumptions beyond those that are required for unbiased estimation of total effects, including that there are no unmeasured confounders (Cole \& Hernan, 2002), that there is no unit-level synergism between exposure and intermediates in the causation of the outcome, and that intermediates are not misclassified (Kaufman, Maclehose, \& Kaufman, 2004). Nevertheless, if hypertension or diabetes are truly causal mediators of the association between socioeconomic position and kidney disease, if the no-confounding conditions are satisfied and if none of the effects are preventive, then adjustment for these intermediates should attenuate the estimated exposure effects. Attenuations are reported in percent reductions in the log of the odds ratio (OR), and are compared to age-adjusted logORs unless otherwise noted.

Model fit was compared between models using a likelihood ratio test (Kleinbaum, Klein, \& Pryor, 2002). Tests of interactions between socioeconomic variables, age, and gender were also conducted using the likelihood ratio test. A $p$-value of 0.05 was used as the cutpoint for tests of statistical significance.

\section{Results}

There were 219 (2.3\%) prevalent CKD cases observed among Whites and 157 (4.9\%) among African-Americans. Table 2 reports the age-adjusted distribution of clinical and demographic attributes overall and by cases status. Compared to non-cases, cases were older, had lower HDL cholesterol, had higher BMI, and were more likely to have diabetes and/or hypertension and be non-drinkers; African-American cases were also more likely than non-cases to be current smokers. Table 3 reports the age-adjusted distribution of socioeconomic attributes overall and by cases status. Cases were more likely than non-cases to be working class at all periods across the life course.

Table 4 shows the measures of association between social class and CKD using the cumulative model. Among Whites, there was a $40 \%$ increase in CKD odds associated with being working class at either some or all periods, compared to being non-working class at all periods ( $p$-value for trend 0.04). By our definition, the "working class" lacked power along all three dimensions constituting social class 
Table 2

Means and proportions of subjects' clinical and demographic characteristics, by race and disease status

\begin{tabular}{|c|c|c|c|c|c|c|c|c|}
\hline & \multicolumn{4}{|l|}{ Whites } & \multicolumn{4}{|c|}{ African-Americans } \\
\hline & $\begin{array}{l}\text { Overall } \\
(n=9449)\end{array}$ & $\begin{array}{l}\text { Non-cases } \\
(n=9230)\end{array}$ & $\begin{array}{l}\text { Cases } \\
(n=219)\end{array}$ & $p$ & $\begin{array}{l}\text { Overall } \\
(n=3221)\end{array}$ & $\begin{array}{l}\text { Non-cases } \\
(n=3064)\end{array}$ & $\begin{array}{l}\text { Cases } \\
(n=157)\end{array}$ & $p$ \\
\hline BMI $\left(\mathrm{kg} / \mathrm{m}^{2}\right)$ at visit 1, mean $(\mathrm{sd})$ & $27.0(2.2)$ & $26.9(4.8)$ & $29.0(6.2)$ & $<0.01$ & $29.8(2.7)$ & $29.7(6.1)$ & $31.9(6.2)$ & $<0.01$ \\
\hline HDL cholesterol at visit 1, mean (sd) & $51.2(7.5)$ & $51.3(16.9)$ & $43.3(15.1)$ & $<0.01$ & $55.4(7.8)$ & $55.7(17.5)$ & $49.7(17.5)$ & $<0.01$ \\
\hline Age at visit 1, mean (sd) & $53.9(5.6)$ & $53.8(5.6)$ & $57.1(4.9)$ & $<0.01$ & $52.8(5.7)$ & $52.8(5.6)$ & $54.5(5.8)$ & $<0.01$ \\
\hline $\begin{array}{l}\text { MDRD GFR }\left(\mathrm{ml} / \mathrm{min} / 1.73 \mathrm{~m}^{2}\right) \text { at } \\
\text { first visit, mean }(\mathrm{sd})\end{array}$ & $89.5(7.7)$ & $89.6(17.1)$ & $80.8(20.9)$ & $<0.01$ & $103.5(11.2)$ & $103.9(24.6)$ & $91.0(36.6)$ & $<0.01$ \\
\hline Male gender, \% & 45.6 & 45.5 & 48.9 & 0.71 & 35.3 & 35.3 & 36.4 & 0.92 \\
\hline Diabetes at visit $1, \%$ & 7.4 & 6.9 & 29.3 & $<0.01$ & 16.1 & 14.3 & 52.1 & $<0.01$ \\
\hline Hypertension at visit $1, \%$ & 25.4 & 24.7 & 47.3 & $<0.01$ & 54.3 & 53.1 & 76.2 & $<0.01$ \\
\hline Diabetes and hypertension, \% & 3.3 & 2.9 & 17.1 & $<0.01$ & 11.1 & 9.5 & 42.0 & $<0.01$ \\
\hline Current drinker, \% & 65.4 & 65.8 & 53.4 & $<0.01$ & 29.7 & 30.0 & 21.9 & 0.08 \\
\hline Current smoker, \% & 21.2 & 21.1 & 24.0 & 0.50 & 25.7 & 25.5 & 28.0 & $<0.01$ \\
\hline
\end{tabular}

Notes: All non-age values are adjusted for mean age at baseline. Abbreviations used in this table: sd=standard deviation; BMI = body mass index; $\mathrm{HDL}=$ high density lipoprotein cholesterol; MDRD GFR = modification of diet in renal disease glomerular filtration rate estimating equation.

(skills, authority, and ownership). Increasing life-periods spent in the working class thus means decreasing periods with at least some degree of power. Adjustment for age, gender, study center, area-level SES hardly attenuated the ORs; the associations were largely independent of diabetes and hypertension. Similar yet stronger associations were seen among African-Americans, who showed a graded response to increasing odds of CKD by increasing proportion of the life course spent in the working class ( $p$ for trend $<0.01)$. Although we failed to formally detect heterogeneity by race ( $p=0.22$ for interaction of African-American race with the term for being working class at all or some periods), this test was underpowered. Among both races, the cumulative effects of living in a low SES area were inconsistent and not statistically significant. Age-adjusted results were similar when we used only ICD-9 code for CKD as an outcome: $p$ for trend was significant for cumulative periods spent as working class among Whites $(p=0.02)$ and African-Americans $(p<0.01)$. Using only the GFRbased definition, $p$ for trend for cumulative working class periods was significant among Whites $(p<0.01)$ but not African-Americans $(p=0.15)$. No significant trends were seen for cumulative burden of living in a low SES area in either race according to any outcome definition.

The addition of interaction terms between individual and contextual socioeconomic variables and gender, age, and each other did not significantly improve the fit of any of the models. Odds ratios obtained using the completecase (non-imputed) data set were similar to the imputed results for both class and area SES. Finally, we compared our results with those obtained using the cutpoint of CKD Stage 3 or higher, $60 \mathrm{ml} / \mathrm{min} / 1.73 \mathrm{~m}^{2}$, which has been employed in numerous other studies, including ARIC. Using this definition, there was no association between life course social class and CKD. Analyses were repeated using an ICD-9 definition alone, and eGFR $<45 \mathrm{ml} / \mathrm{min} / 1.73 \mathrm{~m}^{2}$ alone. Using only ICD-9 code, associations were consistent with the results for the primary outcome among AfricanAmericans, and stronger among Whites. Using only eGFR $<45 \mathrm{ml} / \mathrm{min} / 1.73 \mathrm{~m}^{2}$, there were no associations

Table 3

Means and proportions of subjects' socioeconomic characteristics, by race and disease status

\begin{tabular}{|c|c|c|c|c|c|c|c|c|}
\hline & \multicolumn{4}{|l|}{ Whites } & \multicolumn{4}{|c|}{ African-Americans } \\
\hline & $\begin{array}{l}\text { Overall } \\
(n=9449)\end{array}$ & $\begin{array}{l}\text { Non-cases } \\
(n=9230)\end{array}$ & $\begin{array}{l}\text { Cases } \\
(n=219)\end{array}$ & $p$ & $\begin{array}{l}\text { Overall } \\
(n=3221)\end{array}$ & $\begin{array}{l}\text { Non-cases } \\
(n=3064)\end{array}$ & $\begin{array}{l}\text { Cases } \\
(n=157)\end{array}$ & $p$ \\
\hline \multicolumn{9}{|l|}{ Area SES scores } \\
\hline Age 10 area score, mean (sd) & $0.4(2.9)$ & $0.4(2.9)$ & $0.4(3.0)$ & 0.41 & $-1.3(3.0)$ & $-1.3(3.0)$ & $-1.3(2.5)$ & 0.75 \\
\hline Age 30 area score, mean (sd) & $0.6(2.6)$ & $0.6(2.5)$ & $0.2(2.7)$ & $<0.01$ & $-1.9(4.3)$ & $-1.9(4.1)$ & $-2.1(3.1)$ & 0.65 \\
\hline Age 40 area score, mean (sd) & $0.7(2.2)$ & $0.7(2.2)$ & $0.3(2.1)$ & $<0.01$ & $-2.3(2.5)$ & $-2.2(2.5)$ & $-2.6(2.2)$ & 0.03 \\
\hline Age 50 area score, mean (sd) & $1.1(1.7)$ & $1.1(1.8)$ & $0.7(1.8)$ & $<0.01$ & $-3.3(2.8)$ & $-3.3(2.8)$ & $-3.8(2.7)$ & $<0.01$ \\
\hline \multicolumn{9}{|c|}{ Cumulative working class (father, subject) } \\
\hline Always working class (\%) & 8.4 & 8.3 & 9.7 & 0.63 & 25.6 & 25.1 & 35.4 & $<0.01$ \\
\hline Some periods working class (\%) & 50.7 & 37.0 & 57.9 & 0.02 & 55.1 & 55.3 & 49.5 & 0.56 \\
\hline \multirow[t]{2}{*}{ Never working class (\%) } & 40.9 & 59.6 & 32.4 & 0.02 & 19.0 & 19.3 & 14.8 & 0.19 \\
\hline & $p$ for trend & & & 0.04 & $p$ for trend & & & $<0.01$ \\
\hline \multicolumn{9}{|l|}{ Cumulative low area tertile } \\
\hline All periods low SES (\%) & 21.2 & 21.2 & 22.0 & 0.55 & 23.2 & 23.0 & 27.1 & 0.23 \\
\hline Some periods low SES (\%) & 49.5 & 49.5 & 53.7 & 0.41 & 47.2 & 47.1 & 49.6 & 0.73 \\
\hline \multirow[t]{2}{*}{ No periods low SES (\%) } & 29.3 & 29.3 & 24.3 & 0.19 & 29.7 & 30.0 & 23.3 & 0.13 \\
\hline & $p$ for trend & & & 0.20 & $p$ for trend & & & 0.09 \\
\hline
\end{tabular}

All values are adjusted for age at visit 1 . Abbreviations used: $s d=$ standard deviation; $\mathrm{SES}=$ socioeconomic status. 
Table 4

Odds ratio (95\% confidence interval) of chronic kidney disease, cumulative social class and area socioeconomic status

\begin{tabular}{|c|c|c|c|c|c|c|c|c|c|c|c|}
\hline \multirow[b]{2}{*}{ Adjusted for: } & \multicolumn{5}{|l|}{ Whites } & \multicolumn{6}{|c|}{ African-Americans } \\
\hline & Age & \multicolumn{2}{|c|}{ Model 2: confounders } & \multicolumn{2}{|c|}{ Model 3: Model 2 + DM, HTN } & Age & & \multicolumn{2}{|c|}{ Model 2: confounders } & \multicolumn{2}{|c|}{ Model 3: Model $2+$ DM, HTN } \\
\hline \multicolumn{12}{|c|}{ Cumulative working class } \\
\hline All periods & $1.4(1.0,2.1)$ & 1.4 & $(0.9,2.0)$ & 1.3 & $(0.9,1.9)$ & 2.1 & $(1.4,3.1)$ & 1.9 & $(1.3,2.9)$ & 1.8 & $(1.2,2.7)$ \\
\hline Some periods & $1.4(1.0,1.9)$ & 1.3 & $(1.0,1.9)$ & 1.2 & $(0.9,1.7)$ & 1.5 & $(1.0,2.4)$ & 1.4 & $(0.9,2.2)$ & 1.3 & $(0.8,2.2)$ \\
\hline No periods & 1.0 Ref. & 1.0 & Ref. & 1.0 & Ref. & 1.0 & Ref. & 1.0 & Ref. & 1.0 & Ref. \\
\hline$p$ for trend & 0.04 & 0.07 & & 0.17 & & $<0.0$ & & $<0.01$ & & $<0.01$ & \\
\hline \multicolumn{12}{|c|}{ Cumulative low area SES tertile } \\
\hline All periods & $1.4(0.8,2.4)$ & 1.2 & $(0.7,2.2)$ & 1.1 & $(0.6,2.0)$ & 1.5 & $(0.9,2.4)$ & 1.3 & $(0.8,2.0)$ & 1.1 & $(0.7,1.9)$ \\
\hline Some periods & $1.3(0.9,2.1)$ & 1.3 & $(0.8,2.1)$ & 1.2 & $(0.8,2.0)$ & 1.3 & $(0.8,2.1)$ & 1.2 & $(0.7,1.9)$ & 1.2 & $(0.8,1.9)$ \\
\hline No periods & 1.0 Ref. & 1.0 & Ref. & 1.0 & Ref. & 1.0 & Ref. & 1.0 & Ref. & 1.0 & Ref. \\
\hline$p$ for trend & 0.20 & 0.53 & & 0.69 & & 0.09 & & 0.38 & & 0.66 & \\
\hline
\end{tabular}

First column within each race stratum, marked "age-adjusted", is adjusted only for age.

Model 2: adjusted for age at visit 1, gender, cumulative exposure to working class and low area SES tertile, father farming, and center.

Model 3: Model $2+$ diabetes mellitus (DM) and hypertension (HTN) at visit 1.

a Chronic kidney disease (CKD) defined as GFR $<45 \mathrm{ml} / \mathrm{min} / 1.73 \mathrm{~m}^{2}$, or a hospital discharge diagnosis of CKD.

among Whites, and slightly attenuated results among African-Americans.

\section{Discussion}

To our knowledge, this is the first report documenting that being working class over the life course is associated with adult CKD. The number of periods a person was working class over the life course was generally related to CKD in adulthood in a graded manner; this dose response was statistically significant among African-Americans. The cumulative association of living in a low SES area with CKD risk was weak and not statistically significant. Neither confounding (by age, gender and study center) nor mediators (hypertension and diabetes) accounted for these associations.

Our analysis employed a novel measure of social class. Socioeconomic position is often assessed using a continuous measure of SES, such as years of education or household income (Lynch \& Kaplan, 2000). Class analysts, such as Wright $(1989,1996)$, favor using instruments that measure relationships of authority, decision-making, ownership, and skill level. Social class was dichotomized into working class and non-working class, which is an admittedly crude approach. Nevertheless, we have found noteworthy effects for being working class over sustained periods. This approach has been successfully employed in several recent reports using the ARIC Life Course data to study subclinical atherosclerosis (Carson et al., 2007) and markers of inflammation (Pollitt et al., 2007).

We interpret these findings as evidence that kidney disease is an instance of a health inequity. Health inequalities are not in and of themselves unjust; they only become inequities when they are "avoidable, unnecessary, and unfair" (Daniels, Kennedy, \& Kawachi, 1999, p. 225). In the introductory chapter of Class Counts, Erik Olin Wright argues that exploitation is not merely a technical issue, as the concept "adds a sharp moral judgment to the analytical claim [of class analysis]" (Wright, 1996, p. 13). The disadvantaged and disempowered position of people from working class backgrounds highlights the unfairness of class inequities in kidney disease.
There have been several studies of socioeconomic circumstances and chronic kidney disease (Fored et al., 2003; Krop et al., 1999), albuminuria (Martins et al., 2006), and ESRD (Byrne et al., 1994; Klag et al., 1997; Perneger et al., 1995b), all of which found positive associations with low SES. None of these studies, however, employed a life course assessment or measured social class based on workplace roles, and they failed to separate individual from contextual socioeconomic characteristics. A study by Merkin and colleagues using the parent ARIC cohort found an association between area SES and incident CKD, but only among white men (Merkin, Coresh, Roux, Taylor, \& Powe, 2005). Our study findings most likely differ from Merkin and colleagues due to their use of incident CKD over 9 years of follow-up, whereas our results are based on life course exposures and prevalent CKD as the outcome; additional differences included case and exposure definitions and adjustment factors.

The cumulative working class model offers support in favor of a socioeconomic etiology of CKD. Being working class early in the life course may initiate CKD through several mechanisms, including hypertension and diabetes, reduced nephron number, exposure to nephrotoxins such as heavy metals and analgesics, and poor diet and health behaviors. Kidney disease could well begin during gestation, as individual and area social conditions have been shown to influence birth weight and term (Messer, Kaufman, Dole, Savitz, \& Laraia, 2006; O’Campo, Xue, Wang, \& Caughy, 1997). Animal and human studies have shown a relationship of intrauterine or early life exposures with nephron count (Jones, Bilous, Flyvbjerg, \& Marshall, 2001; Mañalich, Reyes, Herrera, Melendi, \& Fundora, 2000; Vehaskari, Aviles, \& Manning, 2001; Yudkin, Phillips, \& Stanner, 1997) and adult kidney disease (Brenner \& Gertow, 1994; Lackland, Bendall, Osmond, Egan, \& Barker, 2000; Yudkin et al., 1997). Chronic disease risk may then increase as disadvantage becomes embodied over time. Access to care (as measured by rural location and physician concentration) has been associated with progression to ESRD (Fan et al., 2007; Powe, Tarver-Carr, Eberhardt, \& Brancati, 2003); inadequate access may also be linked to earlier stages of CKD. 
The cumulative burden model is not only biologically plausible; it is also consistent with social theory, particularly with Bourdieu's theory of habitus (Bourdieu, 1984). Bourdieu argued that tastes for both "high" culture, as well as the more mundane cultural practices such as eating habits, are acquired early in life: "Bourgeois culture ... [is] acquired, pre-verbally, by early immersion in a world of cultivated people, practices, and objects" (Bourdieu, 1984, p. 75). Lynch and colleagues have shown that these associations are not confined to the rarefied world of the French bourgeoisie, and early life provides an answer to the question "why do poor people behave poorly": Finnish men who grew up impoverished are more likely to engage in detrimental habits including binge drinking, low physical activity level, and high salt consumption (Lynch et al., 1997). However, Bourdieu does not stop at showing that classes have different propensities for particular habits, and he explicitly denies that class is deterministic of behavior. He further demands that researchers reflect on their own assumptions regarding the relationship between habits and class, because habits can be used to legitimize existing class structure (Bourdieu \& Wacquant, 1992). An exclusive focus on lifestyle determinants of kidney disease may in fact serve to legitimate race and class disparities.

Our study has several limitations. First, the associations we report here are likely to underestimate the true effect of class and residence upon CKD. Subjects were drawn from a closed cohort and had to survive over 10 years of follow-up to be included in the Life Course SES study, enriching the analysis data set with healthy individuals and potentially attenuating the true measures of effect. Although $80 \%$ of the original ARIC cohort completed the Life Course interview, just $46 \%$ of participants who had a CKD hospitalization or death were interviewed. The ability to assess this limitation is a strength of ARIC, but it suggests that future studies should obtain estimates of social class prior to disease onset. Recall of social class and address could differ by case status, and may have further attenuated our results. Attenuation could also occur because we employed county-level information for childhood. Counties are large and heterogeneous areas, hence the use of counties could have limited our ability to detect life course area SES effects. Second, distributions for Whites and African-Americans' neighborhoods necessitated using racespecific quartiles, prohibiting direct comparison of race groups. Due to structural confounding (Oakes, 2006), we could not directly assess whether the socioeconomic conditions in predominantly African-American neighborhoods play a role in kidney disease race disparities. Third, we employed a composite measure of CKD, combining both ICD-9 codes and estimated GFR. Using only the GFR-based outcomes, we found associations to be weaker among Whites and consistent among African-Americans, while ICD-9 based results were consistent with the primary results. Because ICD-9 codes are drawn from hospital discharge databases (reflecting more severe cases of CKD), we conclude that working class status may be most salient for severe kidney disease. This was supported by associations being weaker when a GFR cutoff of 60 was used in sensitivity analyses. Finally, we were missing information and used an imputation technique which assumes that data are missing at random (Royston, 2004; Schafer \& Graham, 2002). Although this assumption could not be directly tested, we believe that the imputation models provided valid estimates, and results were robust to various imputation approaches used in another analyses of these same data (Shoham et al., 2007). In that study, the authors also found that education level (a proxy for lifetime socioeconomic position) yielded similar associations with CKD whether we used imputed or non-imputed data. Finally, while the study is large, CKD is relatively uncommon and socioeconomic status is difficult to measure retrospectively, which limits the power of the study.

In conclusion, we have observed associations between chronic kidney disease and cumulative exposure to working class status among both Whites and African-Americans. Associations for cumulative social class were stronger among African-Americans, who suffer a greater burden of kidney disease. Our findings suggest that inter-generational social class patterns are associated with chronic kidney disease. Through no fault of their own, individuals may inherit susceptibility to kidney disease owing to their social origins, whose long arm reaches into adulthood. Efforts to address disparities in kidney disease cannot focus solely on adult lifestyle risk factors, which often amount to blaming the victim. Social justice and disease prevention would be better served by addressing the socioeconomic inequalities that underlie kidney disease, both in childhood and across the life course. Class is identified with power disequilibria. If class is indeed a causal determinant of kidney disease, then inequalities will persist in the absence of social and power equality. Future research in kidney disease health disparities, and policy recommendations addressing these disparities, must take account of the full effect of the life course on adult health.

\section{References}

AAA (1998). American Anthropological Association Statement on "Race". AAPA. (1996). American Association of Physical Anthropologists statement on biological aspects of race. Am. J. Phys. Anthropol., 101, 569-570.

Anderson, M. J. (2000). Encyclopedia of the U.S. census. Washington, DC: CQ Press.

Barker, D., Osmond, C., \& Law, C. M. (1989). The intrauterine and early postnatal origins of cardiovascular disease and chronic bronchitis. J. Epidemiol. Community Health, 43, 237-240.

Blane, D. (1999). The life course, the social gradient, and health. In M Marmot, \& R. Wilkinson (Eds.), Social determinants of health (pp. 64-80). Oxford, England: Oxford University Press.

Bourdieu, P. (1984). Distinction. Cambridge, MA: Harvard University Press.

Bourdieu, P., \& Wacquant, L. J. D. (1992). An invitation to reflexive sociology. Chicago: University of Chicago Press.

Brancati, F. L., Whelton, P. K., Kuller, L. H., \& Klag, M. J. (1996). Diabetes mellitus, race, and socioeconomic status. A population-based study. Ann. Epidemiol., 6(1), 67-73.

Brenner, B. M., Garcia, D. L., \& Anderson, S. (1988). Glomeruli and blood pressure. Less of one, more the other? Am. J. Hypertens., 1(4 Pt. 1), 335-347.

Brenner, B. M., \& Gertow, G. M. (1994). Congenital oligonephropathy and the etiology of adult hypertension and progressive renal injury. Am. J. Kidney Dis., 23, 171-175.

Byrne, C., Nedelman, J., \& Luke, R. G. (1994). Race, socioeconomic status, and the development of end-stage renal disease. Am. J. Kidney Dis. 23(1), 16-22.

Carson, A. P., Rose, K. M., Catellier, D. J., Kaufman, J. S., Wyatt, S. B., DiezRoux, A. V., et al. (2007). Cumulative socioeconomic status across the 
life course and subclinical atherosclerosis. Ann. Epidemiol., 17(4), 296303.

Cass, A., Cunningham, J., Snelling, P., Wang, Z., \& Hoy, W. (2004). Exploring the pathways leading from disadvantage to end-stage renal disease for indigenous Australians. Soc. Sci. Med., 58(4), 767-785.

Cole, S. R., \& Hernan, M. A. (2002). Fallibility in estimating direct effects. Int. J. Epidemiol., 31(1), 163-165.

Conley, D. (1999). Being black, living in the red: Race, wealth, and social policy in America. Berkeley, Calif: University of California Press.

Connolly, V. M., \& Kesson, C. M. (1996). Socioeconomic status and clustering of cardiovascular disease risk factors in diabetic patients. Diabetes Care, 19(5), 419-422.

Coresh, J., Longenecker, J. C., Miller, E. R., 3rd, Young, H. J., \& Klag, M. J. (1998). Epidemiology of cardiovascular risk factors in chronic renal disease. J. Am. Soc. Nephrol., 9(12 Suppl.), S24-S30.

Daniels, N., Kennedy, B. P., \& Kawachi, I. (1999). Why justice is good for our health: the social determinants of health inequalities. Daedalus, 128(4), 215-251.

Fan, Z. J., Lackland, D. T., Lipsitz, S. R., Nicholas, J. S., Egan, B. M., Tim Garvey, W., et al. (2007). Geographical patterns of end-stage renal disease incidence and risk factors in rural and urban areas of South Carolina. Health Place, 13(1), 179-187.

Fored, C. M., Ejerblad, E., Fryzek, J. P., Lambe, M., Lindblad, P., Nyren, O., et al. (2003). Socio-economic status and chronic renal failure: a population-based case-control study in Sweden. Nephrol. Dial. Transplant., 18(1), 82-88.

Frank, J. W., Cohen, R., Yen, I., Balfour, J., \& Smith, M. (2003). Socioeconomic gradients in health status over 29 years of follow-up after midlife: the Alameda county study. Soc. Sci. Med., 57(12), 2305-2323.

Go, A. S., Chertow, G. M., Fan, D., McCulloch, C. E., \& Hsu, C. Y. (2004) Chronic kidney disease and the risks of death, cardiovascular events, and hospitalization. N. Engl. J. Med., 351(13), 1296-1305.

Horan, P. (1978). Is status attainment research atheoretical? Am. Sociol. Rev., 43, 534-540.

James, S. A., Keenan, N. L., Strogatz, D. S., Browning, S. R., \& Garrett, J. M. (1992). Socioeconomic status, John Henryism, and blood pressure in black adults. The Pitt County Study. Am. J. Epidemiol., 135(1), 59-67.

Jones, C. A., Francis, M. E., Eberhardt, M. S., Chavers, B., Coresh, J., Engelgau, M., et al. (2002). Microalbuminuria in the US population: third National Health and Nutrition Examination Survey. Am. J. Kidney Dis., 39(3), 445-459.

Jones, S. E., Bilous, R. W., Flyvbjerg, A., \& Marshall, S. M. (2001). Intra-uterine environment influences glomerular number and the acute renal adaptation to experimental diabetes. Diabetologia, 44(6), 721-728.

Kaufman, J. S., \& Cooper, R. S. (1999). Seeking causal explanations in social epidemiology. Am. J. Epidemiol., 150(2), 113-120.

Kaufman, J. S., Cooper, R. S., \& McGee, D. L. (1997). Socioeconomic status and health in blacks and whites: the problem of residual confounding and the resiliency of race. Epidemiology, 8(6), 621-628.

Kaufman, J. S., Maclehose, R. F., \& Kaufman, S. (2004). A further critique of the analytic strategy of adjusting for covariates to identify biologic mediation. Epidemiol. Perspect. Innov., 1(1), 4

Klag, M. J., Whelton, P. K., Randall, B. L., Neaton, J. D., Brancati, F. L., \& Stamler, J. (1997). End-stage renal disease in African-American and white men: 16-year MRFIT findings. JAMA, 277(16), 1293-1298.

Kleinbaum, D. G., Klein, M., \& Pryor, E. R. (2002). Logistic regression: A selflearning text. New York: Springer.

Krop, J. S., Coresh, J., Chambless, L. E., Shahar, E., Watson, R. L., Szklo, M., et al. (1999). A community-based study of explanatory factors for the excess risk for early renal function decline in blacks vs whites with diabetes: the Atherosclerosis Risk in Communities study. Arch. Intern. Med., 159(15), 1777-1783.

Lackland, D. T., Bendall, H. E., Osmond, C., Egan, B. M., \& Barker, D. J (2000). Low birth weights contribute to high rates of early-onset chronic renal failure in the Southeastern United States. Arch. Intern. Med., 160(10), 1472-1476.

Levey, A. S., Coresh, J., Greene, T., Stevens, L. A., Zhang, Y. L., Hendriksen, S. et al. (2006). Using standardized serum creatinine values in the modification of diet in renal disease study equation for estimating glomerular filtration rate. Ann. Intern. Med., 145(4), 247-254.

Link, B. G., \& Phelan, J. (1995). Social conditions as fundamental causes of disease. J. Health Soc. Behav., Spec No., 80-94.

Lynch, J. W., \& Kaplan, G. A. (2000). Socioeconomic position. In L. Berkman, \& I. Kawachi (Eds.), Social epidemiology (pp. 13-35). New York: Oxford University Press.

Lynch, J. W., Kaplan, G. A., \& Salonen, J. T. (1997). Why do poor people behave poorly? Variation in adult health behaviours and psychosocial characteristics by stages of the socioeconomic lifecourse. Soc. Sci. Med., 44(6), 809-819.
Mañalich, R., Reyes, L., Herrera, M., Melendi, C., \& Fundora, I. (2000). Relationship between weight at birth and the number and size of renal glomeruli in humans: a histomorphometric study. Kidney Int., 58(2), 770-773.

Martins, D., Tareen, N., Zadshir, A., Pan, D., Vargas, R., Nissenson, A., et al. (2006). The association of poverty with the prevalence of albuminuria: data from the Third National Health and Nutrition Examination Survey (NHANES III). Am. J. Kidney Dis., 47(6), 965-971.

Merkin, S. S., Coresh, J., Roux, A. V., Taylor, H. A., \& Powe, N. R. (2005). Area socioeconomic status and progressive CKD: the Atherosclerosis Risk in Communities (ARIC) Study. Am. J. Kidney Dis., 46(2), 203-213.

Messer, L. C., Kaufman, J. S., Dole, N., Savitz, D. A., \& Laraia, B. A. (2006). Neighborhood crime, deprivation, and preterm birth. Ann. Epidemiol., 16(6), 455-462.

NKF. (2002). K/DOQI clinical practice guidelines for chronic kidney disease: evaluation, classification, and stratification. Kidney Disease Outcome Quality Initiative. Am. J. Kidney Dis., 39(Suppl. 2), S1-S246.

O'Campo, P., Xue, X., Wang, M. C., \& Caughy, M. (1997). Neighborhood risk factors for low birthweight in Baltimore: a multilevel analysis. Am. J. Public Health, 87(7), 1113-1118.

Oakes, J. M. (2006). Commentary: advancing neighbourhood-effects research-selection, inferential support, and structural confounding. Int. J. Epidemiol., 35(3), 643-647.

Oakes, J. M., \& Rossi, P. H. (2003). The measurement of SES in health research: current practice and steps toward a new approach. Soc. Sci. Med., 56(4), 769-784

Oliver, M. L., \& Shapiro, T. M. (1995). Black wealth/white wealth: A new perspective on racial inequality. New York: Routledge.

Pearl, J. (2000). Causality: Models, reasoning, and inference. Cambridge, UK; New York: Cambridge University Press.

Perneger, T. V., Klag, M. J., \& Whelton, P. K. (1995a). Race and socioeconomic status in hypertension and renal disease. Curr. Opin. Nephrol. Hypertens., 4(3), 235-239.

Perneger, T. V., Whelton, P. K., \& Klag, M. J. (1995b). Race and end-stage renal disease. Socioeconomic status and access to health care as mediating factors. Arch. Intern. Med., 155(11), 1201-1208.

Pickering, T. (1999). Cardiovascular pathways: socioeconomic status and stress effects on hypertension and cardiovascular function. Ann. N.Y. Acad. Sci., 896, 262-277.

Pollitt, R. A., Kaufman, J. S., Rose, K. M., Diez-Roux, A. V., Zeng, D., \& Heiss, G. (2007). Early-life and adult socioeconomic status and inflammatory risk markers in adulthood. Eur. J. Epidemiol., 22(1), 55-66.

Powe, N. R., Tarver-Carr, M. E., Eberhardt, M. S., \& Brancati, F. L. (2003). Receipt of renal replacement therapy in the United States: a population-based study of sociodemographic disparities from the Second National Health and Nutrition Examination Survey (NHANES II). Am. J. Kidney Dis., 42(2), 249-255.

Robbins, J. M., Vaccarino, V., Zhang, H., \& Kasl, S. V. (2001). Socioeconomic status and type 2 diabetes in African American and non-Hispanic white women and men: evidence from the Third National Health and Nutrition Examination Survey. Am. J. Public Health, 91(1), 76-83.

Robins, J. M., \& Greenland, S. (1992). Identifiability and exchangeability for direct and indirect effects. Epidemiology, 3(2), 143-155.

Rothman, K. J., \& Greenland, S. (1998). Precision and validity in epidemiologic studies. In K. J. Rothman, \& S. Greenland (Eds.), Modern epidemiology (pp. 115-134). Philadelphia, PA: Lippincott-Raven.

Royston, P. (2004). Multiple imputation of missing values. STATA J., 4(3), 227-241.

Schafer, J. L., \& Graham, J. W. (2002). Missing data: our view of the state of the art. Psychol. Methods, 7(2), 147-177.

Shoham, D. A., Vupputuri, S., Diez Roux, A. V., et al. (2007). Kidney disease in life-course socioeconomic context: the Atherosclerosis Risk in Communities (ARIC) Study. Am. J. Kidney Dis., 49(2), 217-226.

Shoham, D. A., Vupputuri, S., \& Kshirsagar, A. V. (2005). Chronic kidney disease and life course socioeconomic status: a review. Adv. Chronic Kidney Dis., 12(1), 56-63.

Stevens, L. A., Coresh, J., Greene, T., \& Levey, A. S. (2006). Assessing kidney function-measured and estimated glomerular filtration rate. N. Engl. J. Med., 354(23), 2473-2483.

The ARIC Investigators. (1989). The Atherosclerosis Risk in Communities (ARIC) Study: design and objectives. Am. J. Epidemiol., 129(4), 687702.

USRDS (2003). United States Renal Data System 2003 Annual Data Report.

USRDS. (2004). 2004 Annual data report: Atlas of end-stage renal disease in the United States. Bethesda, MD: National Institutes of Health, National Institute of Diabetes and Digestive and Kidney Diseases.

Vehaskari, V. M., Aviles, D. H., \& Manning, J. (2001). Prenatal programming of adult hypertension in the rat. Kidney Int., 59(1), 238-245. 
Vupputuri,S., Batuman, V., Muntner, P., Bazzano, L. A. Lefante, J.J., Whelton, P. K., et al. (2003). Effect of blood pressure on early decline in kidney function among hypertensive men. Hypertension, 42(6), 1144-1149.

Whitsel, E. A., Rose, K. M., Wood, J. L., Henley, A. C., Liao, D., \& Heiss, G. (2004). Accuracy and repeatability of commercial geocoding. Am. J. Epidemiol., 160(10), 1023-1029.

Wilson, W. J. (1990). The truly disadvantaged. Chicago: University of Chicago Press.
Wohlfarth, T. (1997). Socioeconomic inequality and psychopathology: are socioeconomic status and social class interchangeable? Soc. Sci. Med., 45(3), 399-410.

Wright, E. O. (1989). Classes. London: Verso.

Wright, E. O. (1996). Class counts. New York: Cambridge University Press. Yudkin, J. S., Phillips, D. I., \& Stanner, S. (1997). Proteinuria and progressive renal disease: birth weight and microalbuminuria. Nephrol. Dial. Transplant., 12(Suppl. 2), 10-13. 